\title{
NUMERICAL MODELling OF ALUMiniUm EXTRUSION AND Comparison With ACtual Profile EXTrusion
}

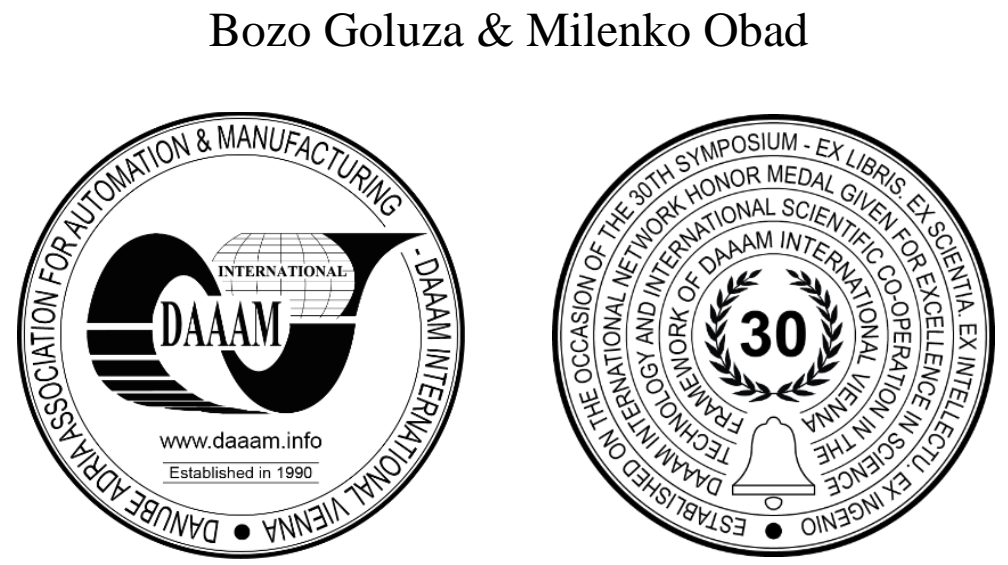

This Publication has to be referred as: Goluza, B[ozo] \& Obad, M[ilenko] (2020). Numerical Modelling of Aluminium Extrusion and Comparison with Actual Profile Extrusion, Proceedings of the 31st DAAAM International Symposium, pp.0423-0430, B. Katalinic (Ed.), Published by DAAAM International, ISBN 978-3-902734-29-7, ISSN 1726-9679, Vienna, Austria

DOI: $10.2507 / 31$ st.daaam.proceedings.059

\begin{abstract}
:
The extrusion process is an attractive method of manufacturing in the industry due to its ability to achieve energy and material save, improve quality, and develop homogeneous properties. With the increasing application of computer techniques in the last decade, a large number of numerical simulations of the pressing process are being conducted to improve product quality and production efficiency. Currently, the most common method for modelling aluminium extrusion problems is the finite element method (FEM). In this paper, a numerical model of aluminium extrusion for a profile of a complex geometric cross-section is developed. The numerical model is then simulated using a numerical model in several phases during extrusion. The numerical results were compared with the experimental results. The comparison shows that the numerical model can be a guideline in optimisation when producing a new die.
\end{abstract}

Keywords: aluminium extrusion; numerical modelling; FEM analysis; optimisation

\section{Introduction}

Aluminium extrusion is one of the conventional methods of the metal forming process. Extrusion is a modern process that came into mass use in 1886 [1], mostly produces flat semi-finished products in the form of hollow and full parts of varying complexity. According to a report by the EAA (Europe Aluminium Association) [2], aluminium products began to be used extensively from 2000 to 2005 . Figure 1 shows the use of aluminium products in various industries.

During the profile extrusion process, an understanding of the metal flow in porthole die cavity is important because it is response to the design of die structure and selection of process parameters. Usually, aluminum profile extrusion is a very complex process of metal flow, which is mainly dependent on the level of the die design. Yet current design of extrusion die structure in extrusion enterprises is primarily based on the trial-and-error method. The performance of the dies to a large extent is determined by the experience of die designers. With this kind of design pattern, it is impossible to guarantee product quality and productivity when the profile structure is more complex and actual production has to be stopped or postponed. With increasing application of computational techniques in recent years, a large number of studies on the numerical simulation of extrusion process have been carried out to improve the product quality and production efficiency. These numerical models are used to predict die stresses, temperature distribution, stress and strain gradients of the extrudate, flow velocities, extrusion pressures, dimensions, and distortions, etc., which are difficult to measure by traditional means. [3]. 


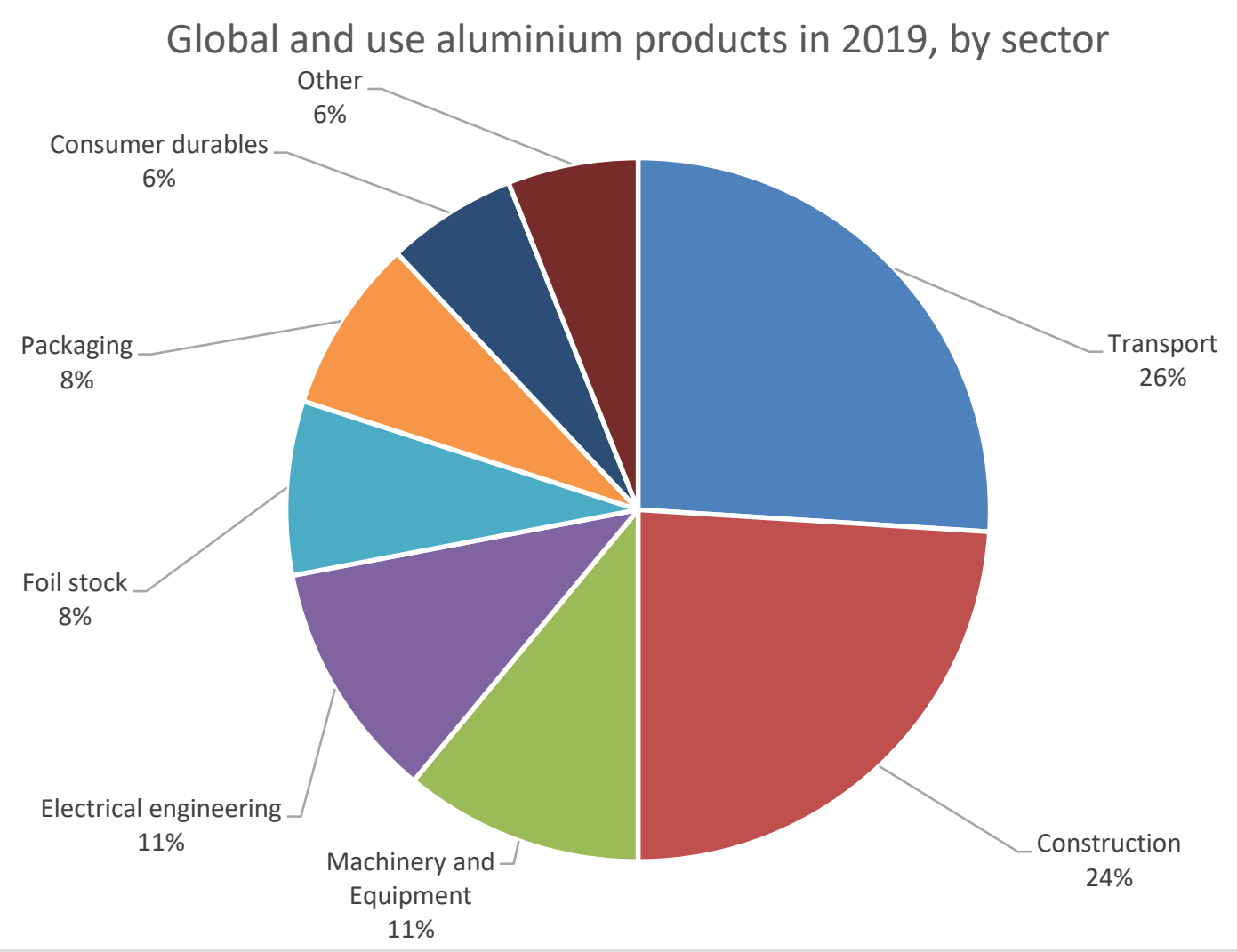

Fig. 1. Use of aluminium in various industries [2]

There are two ways of extruding aluminium, which are shown in Figure 2 [4]:

1. Direct extrusion

2. Indirect extrusion
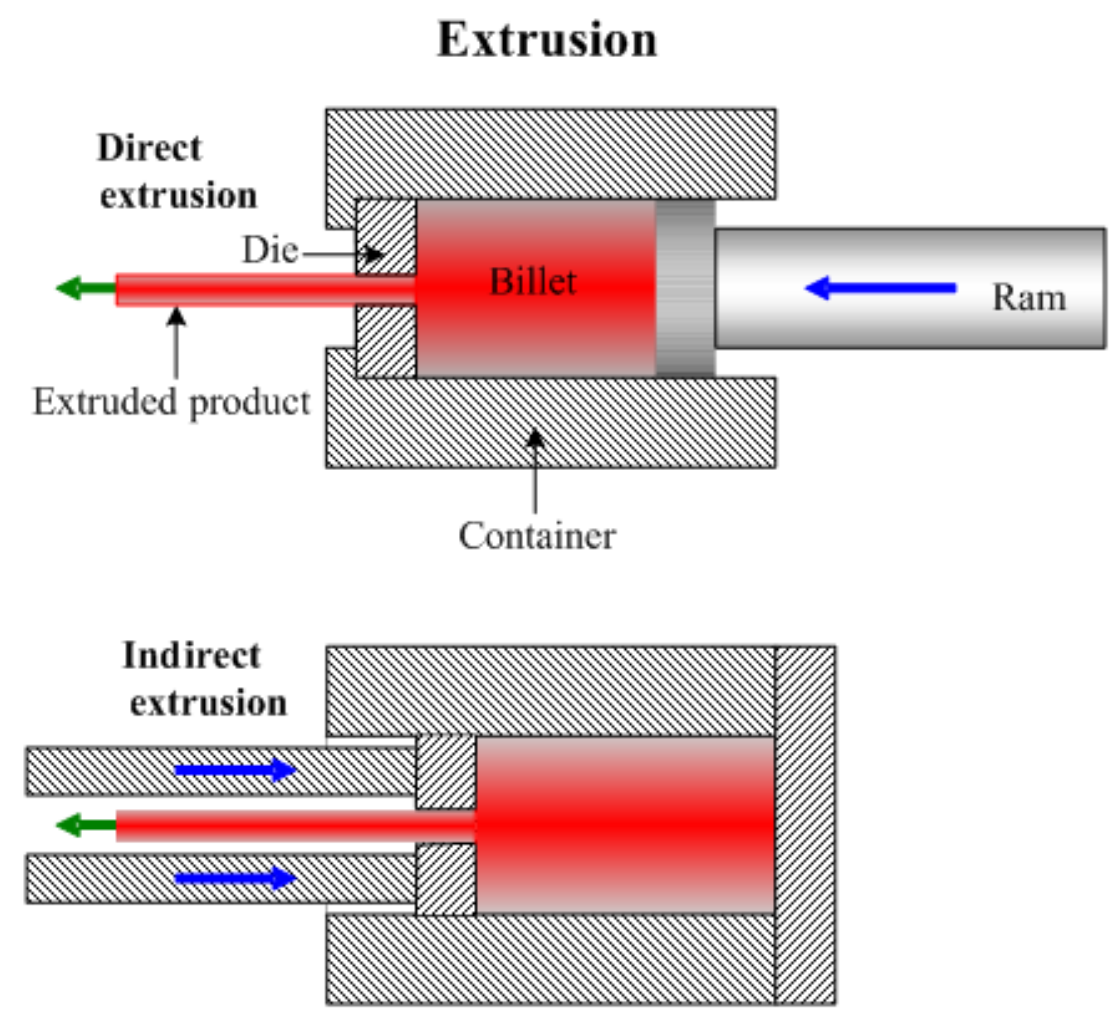

Fig. 2. Two ways of aluminium extrusion: direct and indirect [5] 
The major difference is that in an indirect way, there is no friction between the billet and the container. In the direct mode, the outer shell of the billet moves relative to the container as extrusion proceeds. Many types of errors can occur during the extrusion process, which is not acceptable. One of the types of errors is longitudinal lines. Longitudinal lines can occur in the welding chamber at hollow dies or in any aberration in a solid mould that results in localised high pressure. The defect generally becomes visible after etching. Due to the mentioned problem, the search for possible solutions to the problem was started. One way to describe how to solve this problem is FEM analysis.

In this paper, one of the numerical analysis procedures for aluminium extrusion will be described. The extrusion process is often the most economical way to obtain parts of the continuous cross-section. The result is very solid parts of low weight. AA6XXX alloy series (Al-Mg-Si series) have the largest representation in the aluminium market. More than $80 \%$ of aluminium alloy products in the world are $6 \mathrm{xxx}$ alloy series [6]. The reason why this group is taken is its good properties for production and application. 6xxx series alloys have medium strength, have good machinability and weldability, and are heat treatable.

\section{FEM analysis}

The low availability of numerical analysis in the aluminium extrusion process has led many researchers to design the aluminium extrusion process and simulate it in real extrusion. For modelling of aluminium extrusion analytically, methods such as the slip line field method and the upper limit method are available [7], [8]. These methods are possible only for elementary geometry and are not suitable for most profiles that appear in industrial practice [9]. Currently, the most common method for modelling aluminium extrusion problems is the finite element method (FEM). The finite element method represents a complex geometry in the form of a series of elements of a simple geometric shape that are interconnected at nodes. Loads and boundary conditions are applied at the nodes in such a way as to represent the actual loads and boundary conditions as faithfully as possible.

\section{The flow of material during profile extrusion}

During the profile extrusion process, the flow of the material is important because the shape is recognised and the pressing parameters are selected. Typically, aluminium profile extrusion is a very complex metal flow process that largely depends on the design of the die itself. If the flow velocity in the cross-section of the die outlet is uneven, errors such as twisting, corrugation, cracking and bending are expressed and often ruin the die itself. The current design of the extrusion die structure is based on trial and error methods. The efficiency of the die is largely determined by the experience of the die designer himself. With this design, it is impossible to guarantee product quality and productivity when the profile structure is more complex and actual production has to be stopped or delayed.

Numerical models are used to predict die stresses, temperature distribution, stress and strain gradients during pressing, flow rates, extrusion pressures, dimensions, deformations, which are difficult to measure by standard methods. In addition, the effects of die design and extrusion process parameters on these variables can easily and effectively assume how to optimise die design and process parameters. For this purpose, software packages are used that include several programs designed for different steps in the analysis. Three different dies will be used in this paper to simulate the flow of aluminium alloy materials: HyperMesh, HyperXtrude, and HyperView (as shown in Figure 3) [10], [11]

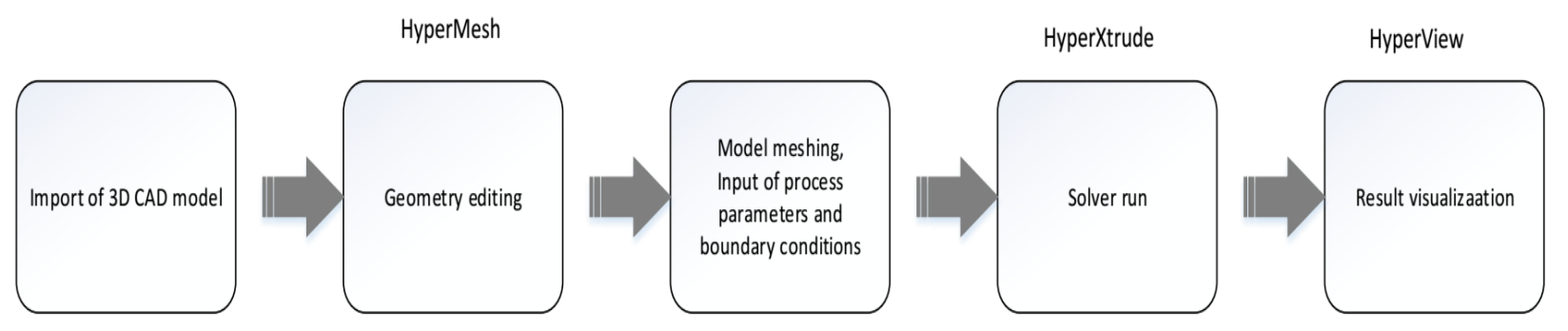

Fig. 3. The material flow simulation scheme

The numerical model was prepared in the HyperMesh program. HyperMesh is a preprocessor and allows interactive data entry. Initially, the 3D CAD model is imported and used to create a finite element network followed by the entry of process parameters such as extrusion speed, die, billet temperature, etc. HyperXtrude is a CAE (Computer Aided Engineering) die that runs the simulation - this is virtual extrusion, which simulates how material flows through the die. The method used for the calculation is the finite element method (FEM). HyperView is a post-processor and allows visualisation of the obtained results. Various scientists have already worked on the introduction of numerical simulations in the extrusion die design process - the process of modelling the components required for simulation [12], [13], die optimisation based on simulation results [12] and simulation of experimental application results [12], [13], [14], [15]. 
Stebunov presented a special program for simulating the extrusion of aluminium profiles and described special modules of that software [16]. Yang et al. developed a finite element-based program to analyse the extrusion process and the effects of material flow through the die [17].

In the past, numerical simulations of aluminium profiles have been limited to relatively simple solid rods and strips or axisymmetric tubes of low extrusion ratios, and the analysis of complex hollow profiles has not much been presented so far. Moreover, the simulation of the extrusion process is mainly based on Lagrangian or Eulerian method in current papers, but both of which have drawbacks. Yet the ALE algorithm (Lagrange-Euler Algorithm) alleviates many of the drawbacks that the traditional Lagrangian and Eulerian based finite element simulations have. It can be used to perform comprehensive engineering simulations, including heat transfer, fluid flow, fluid-structure interactions and metal manufacturing [18].

\section{Extrusion process modelling using HyperExtrude}

Figure 4 shows a cross-section of the profile that was the subject of this study. Dimensions are shown in millimetres.

155

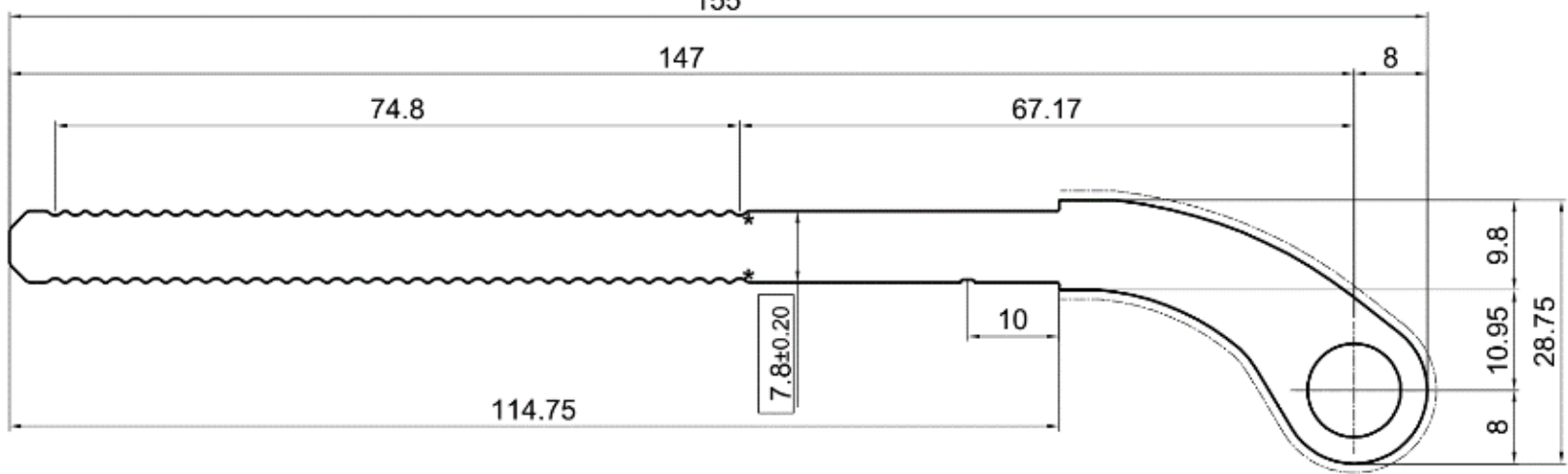

Fig. 4. Dimensions and geometry of the profile

Figure 5 shows the two parts of the die, input part and output part. There are welding points on the input part, which is shown in Figure 5b.

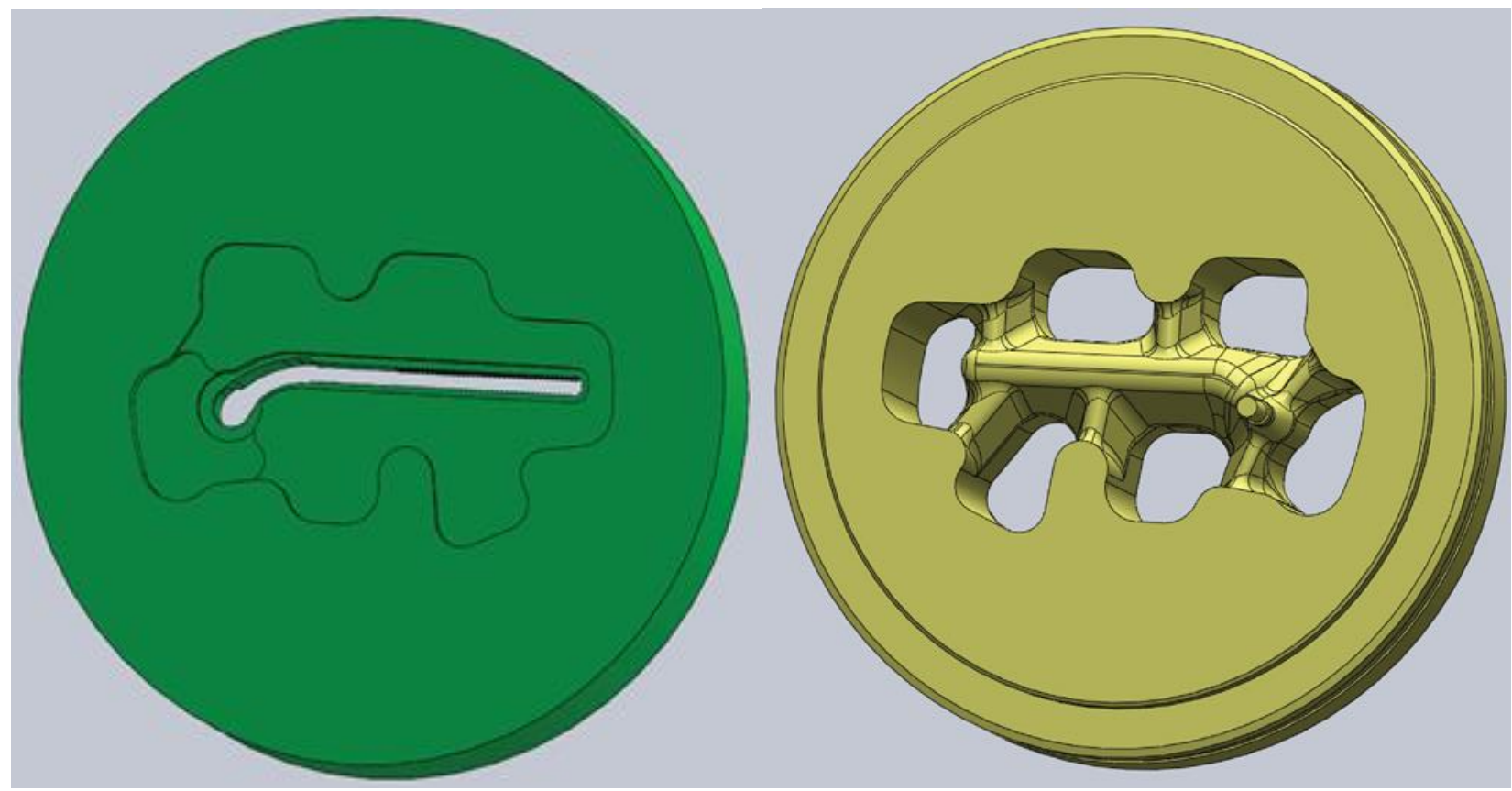

Fig. 5. Extrusion dies a) output part (left) b) input part (right)

During extrusion, the material flows through the inner space between the inlet part and the bearing and takes the form of a pressed profile (Figure 6). 


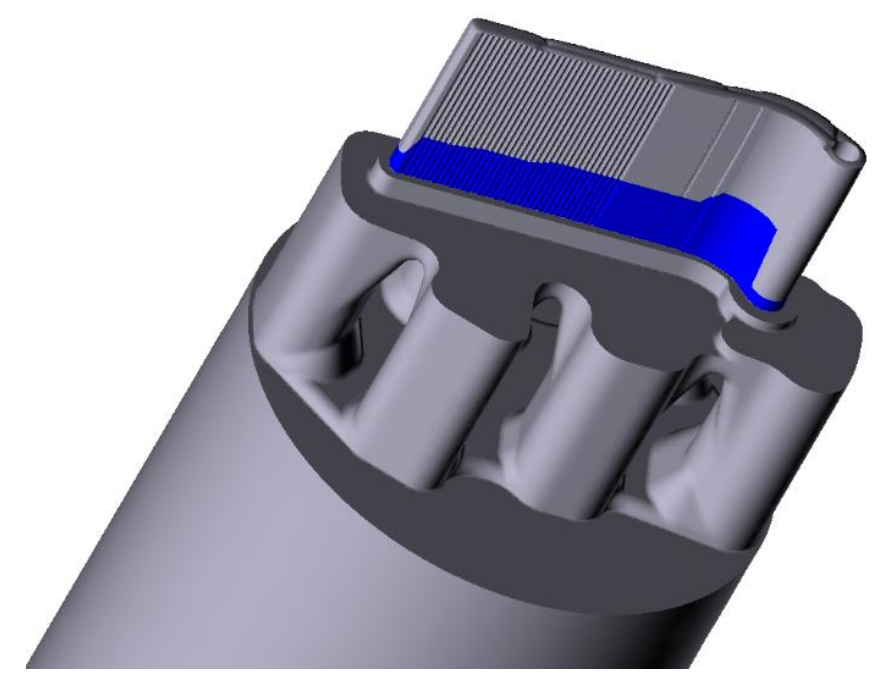

Fig. 6. Flow the material through the die

\subsection{Material flow through the die}

Figure 7 shows the speed distribution of six cross-sections in the direction of extrusion of profiles showing the flow of material throughout the extrusion process. Figure 7.a shows the speed distribution at the input. The contour drawn in Figure 7 shows the scalar value of the velocity on the surface to be extruded (red and blue represent the highest and lowest velocity values). Figure 7.d shows that the metal flows faster in the middle than the one at the ends. This phenomenon is caused by friction (sticky state) against the wall of the opening.

In the extrusion process, the temperature from the hollow part of the die mainly affects the heat transfer friction and the heat of plastic deformation. On the extruded model, the temperature of the material first drops and then goes in the direction of extrusion. The reason is that heat is continuously transferred from the log to the die with a lower temperature.

a)

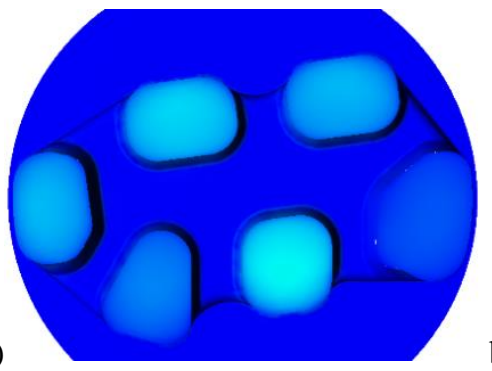

d)

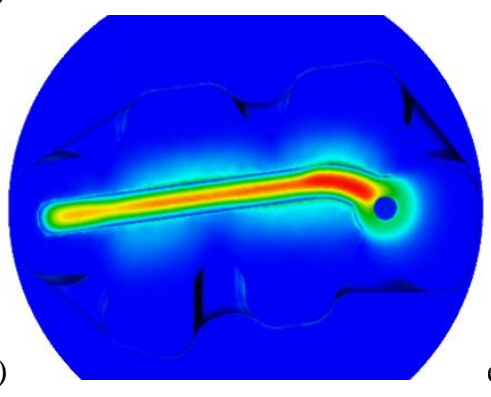

b)

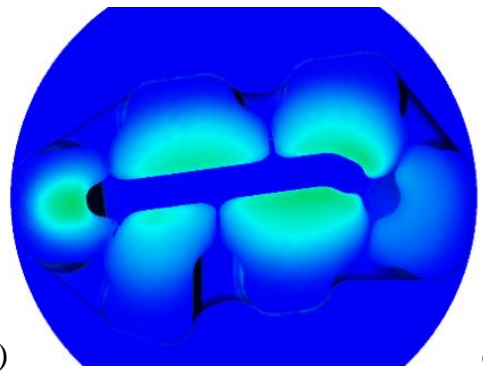

e)

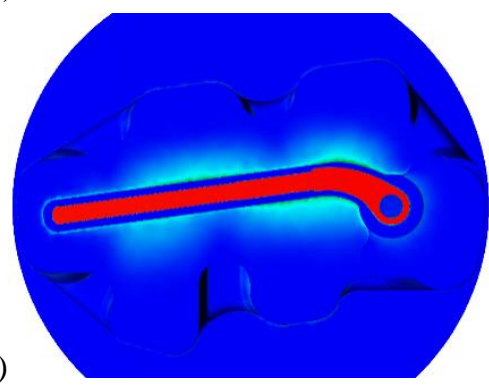

c)

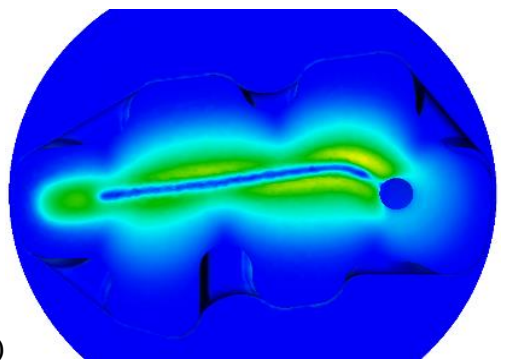

f)

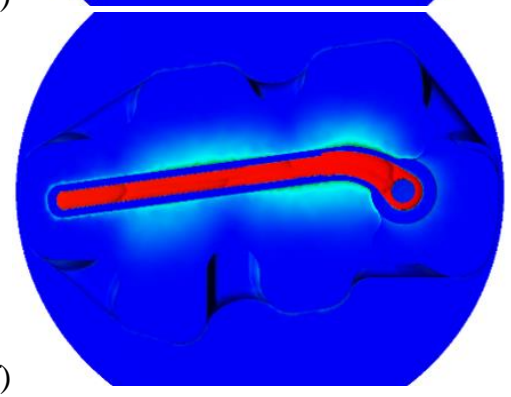

Fig. 7. Flow material in different phases on the die

At the beginning of the extrusion process, the temperature of the billets drops slightly. The billets are then divided into several parts, depending on where it is located. From this point, the plastic deformation is larger than that in the early stage of the extrusion process, so the temperature rises slightly. However, the temperature of the material at this point is still within the initial temperature of the billet. When the material arrives at the welding sites, the plastic deformation becomes larger and larger, as a result of which the temperature of the billet continuously rises along the direction of extrusion. When the material arrives at the die bearings, maximum deformation occurs, and the temperature is highest in this part. From all the above, we can conclude that the increase in temperature of the extruded material is mainly caused by the release of heat from plastic deformation during the extrusion process. 
After a numerical analysis of die manufacturing, a die is produced, and profile extrusion is performed. The process parameters used in finite element simulations and actual production are the same. It is difficult to obtain a good experimental verification of numerical results. However, a rough comparison with the actual speed output can be achieved by comparison with the start of profile pressing [19], which is often used to adjust the die structure. Based on these results, adjustments to the matrix structure, such as slot geometry and size, bearing length, etc., can be made to compensate for this velocity difference. Numerical simulation shows that the flow of material on the die is not uniform which can lead to further problems during aluminum extrusion (Figure 8).

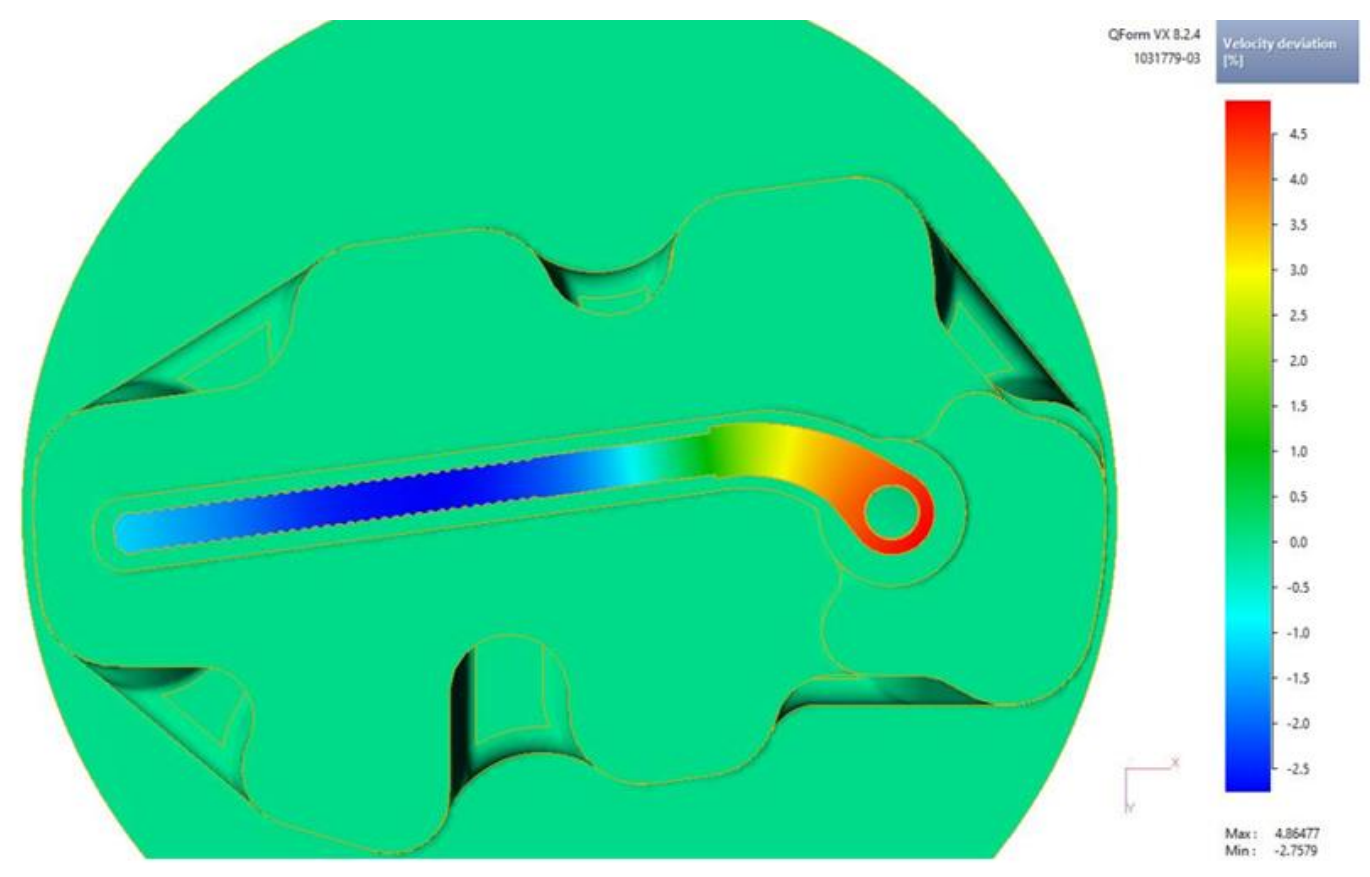

Fig. 8. Material flow rates

The numerical simulation shows the errors at the weld points and possible problems during profile extrusion (Fig 9).

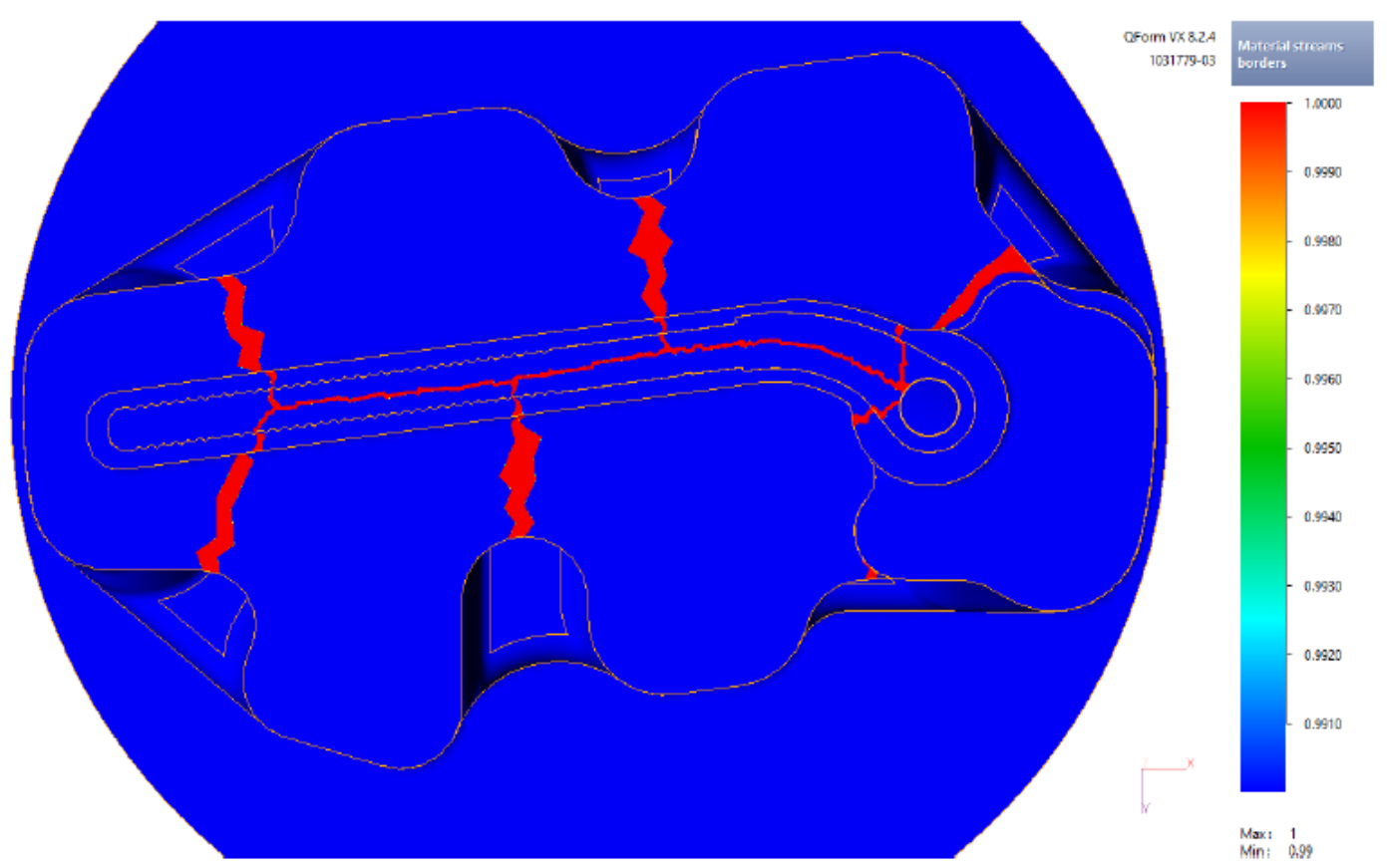

Fig. 9. Welding site

After producing the die and extrusion of the profile, it can be concluded that on the raw profiles at the welding sites, there are longitudinal lines that are visible even after the welding process, as shown by the simulation (Figure 10). 


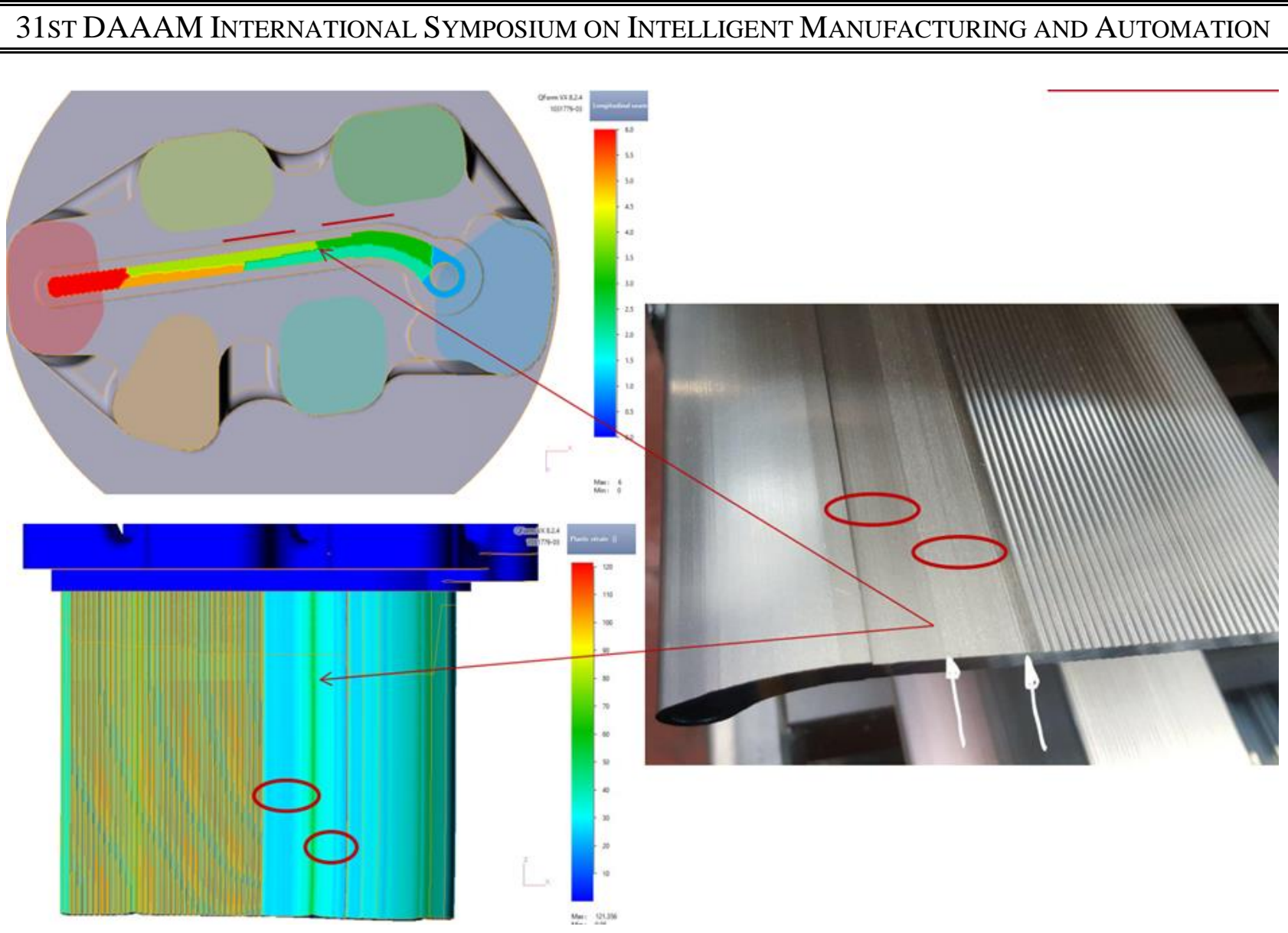

Fig. 10. Representation of profile extrusion simulation and extrusion experiment

From all this, it can be concluded that the numerical model can provide good results and be a useful guideline for practical production.

\section{Conclusion}

In this paper describes the problem of the longitudinal lines on the profiles which are visible after the anodisation process. Due the mention problem, a solution was sought on the FEM analysis. This paper describes in detail the design of the procedure of a numerical model of a complex die. With the commercial program HyperXtrude, the process of extrusion of the aluminium profile was analysed with appropriate boundary conditions, process parameters, etc. The metal flow and its behaviour in the die cavity were investigated at each stage.

A comparison of the results between numerical simulation and practical production showed that the numerical model developed in this paper could be used to investigate metal flow distributions, velocity or temperature and die optimisation. Moreover, the numerical method could partially replace the trial and error method in actual production to improve extrusion quality, improve production capacity and reduce production costs. The conclusion is that the FEM analysis found a place where the problem is beginning. That is on the welding place at the die. The next step is to construct a new die for the extrusion to minimise these longitudinal lines on the profiles.

\section{References}

[1] Sheppard, T. (1999). Extrusion of aluminium Alloys. Kluwer Academic.

[2] European Aluminium Association, Sustainability of the European Aluminium Industry. 2020

[3] Chueseng, Z.; Guoqun, Z.; Hao, C.; Yanjin, G. \& Fujun, K. (2011). Numerical simulation and metal flow analysis of hot extrusion process for a complex hollow aluminium profile, Springer-Verlang London Limited 2011

[4] Garcia-Dominguez, A.; Claver, J.; Camacho, A.M. \& Sebastian, M.A. (2014). Comparative Analysis of Extrusion Processes by Finite Element Analysis. In Proceedings of the 25th DAAAM International Symposium (pp. 74-83). Viena: DAAAM International. https://doi.org/10.1016/j.proeng.2015.01.344

[5] http://www.substech.com (2020). Aluminum_extrusion, Accessed on: 2020-07-15

[6] Al-Marahleh G. (2006). Effect of heat Treatment Parameters on distribution and Volume Fraction of Mg2Si in the Structural Al6063 Alloy, American Journal of applied Sciences, 2006; 3(5):1819-1823

[7] Keife, H. (1993). Extrusion through Two Die Openings: A 2D Upper-Bound Analysis Checked by Plasticine Experiments. Journal of Materials Processing Technology, 1993. 37: p. 189-202. 
[8] Stören, S. (1993). The Theory of Extrusion - Advances and Challenges. International Journal of Mechanical Science, 1993. 35: p. 1007-1020.

[9] Mooi, H.G. (1996). Finite Element Simulations of Aluminium Extrusion. Ph.D. dissertation, University of Twente, Netherland

[10] http://www.altairhyperworks.co.uk (2018). Accessed on: 2018-11-15

[11] http://www.altairhyperworks.co.uk (2018). Accessed on: 2018-11-20

[12] Andredi, T. (2009). Extrusion simulations: a new approach in die-design process, International Conference on Extrusion and Benchmark, Dortmund, Sep. 2009.

[13] Kumar, S. \& Vijay, P. (2007). Die design and experiments for shaped extrusion under cold and hot condition, Journal of Materials Processing Technology, Vol. 190, 375-381.

[14] Krähenbühl, Y. \& Bourqui, B. (2009). Simulation aided extrusion in the design practice, International Conference on Extrusion and Benchmark, Dortmund, Sep. 2009.

[15] Li, G.; Yang, J.; Oh, J. Y.; Foster, M.; Wu, W.; Tsai, P. \& Chang, W. (2009). Advances of Extrusion Simulation in DEFORM-3D, International Conference on Extrusion and Benchmark, Dortmund, Sep. 2009.

[16] Stebunov, S.; Lishnij, A.; Biba, N.; Belotti, S. \& Fazzini, P. (2009). Development and industrial verification of Qformextrusion program for simulation profile extrusion, International Conference on Extrusion and Benchmark, Dortmund, Sep. 2009.

[17] Yang, DY.; Park, K. \& Kang, YS. (2001). Integrated finite element simulation for the hot extrusion of complicated Al alloy profiles. J Mater Process Technol 111:25-30

[18] Kraft, FR. \& Gunasekera, S. (2005). Conventional hot extrusion. In: Semiatin, SL (ed) ASM handbook, volume 14a. Metal working: bulk forming. pp 421-439

[19] Lof, J. \& Blokhuis, Y. (2002). FEM simulations of the extrusion of complex thin-walled aluminium sections. J Mater Process Technol 122:344-354 